\title{
A informação sobre a Covid-19 nos desertos de notícias: a relevância do jornalismo interior do Pará
}

\author{
Information about Covid-19 in news deserts: the importance of \\ journalism in the interior of Pará
}

\author{
Elaine Javorski ${ }^{\mathrm{a}, *}$ (1) \\ Janine Bargas ${ }^{\mathrm{b}}$ (D)
}

\begin{abstract}
RESUMO: Diante da pandemia da COVID-19, o acesso à informação de qualidade tornou-se elemento fundamental na manutenção das condições básicas de saúde. Neste artigo discutimos a importância do jornalismo nos chamados desertos de notícias. Partimos da realidade da cidade de Rondon do Pará, Sudeste paraense, Brasil, para analisar como a escassez de informação jornalística impacta o conhecimento da realidade local, especialmente durante a pandemia. Assumimos a premissa de que o jornalismo, fundamentado em princípios e critérios específicos, tende a produzir informações mais qualificadas do que aquelas difusas em ambientes digitais informais. Assim, nossa hipótese é a de que, em locais com meios jornalísticos diversos, há maior espaço para promoção da cidadania, uma vez que as comunidades podem ter bons subsídios para a tomada de decisões. Embora utilizemos dados quantitativos, nossa metodologia é eminentemente qualitativa, fundamentada em entrevistas semiestruturadas com cidadãos rondonenses, e em observação participante, com nossa experiência na rotina de produção do portal Rondon Notícias. Fundamentadas em conceitos como jornalismo comunitário, regional, desinformação e comunicação para mudança social, observamos a relevância do jornalismo em sociedades periféricas como uma questão de cidadania e de desenvolvimento. Nossa análise aponta, entre outras questões, que em comunidades com pouca tradição de mídias locais, os cidadãos não conseguem diferenciar as informações jornalísticas de outros tipos, diminuindo as chances de estarem bem informados e, em última análise, acessarem sua condição de cidadãos. E, além de não compreenderem a importância da informação local, também não se dispõem como fontes, o que dificulta o exercício do jornalismo nesses espaços.
\end{abstract}

Palavras-chave: Deserto de Notícias; Jornalismo; Desinformação; Rondon Notícias; Covid-19.

ABSTRACT: In the face of the Covid-19 pandemic, the access to quality information has become a fundamental condition to maintain basic health conditions. In this article we discuss the importance of Journalism in the so-called news desert. We start from the reality of the city of Rondon do Pará, southeast of Pará, Brazil, to analyze how the scarcity of journalistic information impacts the knowledge of the local situation, especially during the coronavirus outbreak. We take the assumption that Journalism, established on specific principles and criteria, tends to produce more qualified information than that disseminated in informal digital environments. Thus, our hypothesis is that in places with different journalistic media, there is more space to encourage citizenship, because communities can count on good subsidies to take decisions. Although we use quantitative data, our methodology is highly qualitative, based on semi-structured interviews with inhabitants of Rondon do Pará, and on participant observation, supported by the experience of our production routine at the Portal Rondon Notícias. Well-founded on concepts such as community and regional journalism, misinformation and communication for social change, we consider the relevance of Journalism in outskirts societies as a matter of citizenship and

\footnotetext{
a Programa de Pós-Graduação em Comunicação, Universidade Federal do Maranhão, Imperatriz, MA, Brasil. Faculdade de Comunicação, Universidade Federal do Sul e Sudeste do Pará, Rondon do Pará, PA, Brasil.

b Faculdade de Comunicação, Universidade Federal do Sul e Sudeste do Pará, Rondon do Pará, PA, Brasil.

*Correspondência para/Correspondence to: Elaine Javorski. E-mail: elaine.javorski@unifesspa.edu.br. Endereço institucional: Rua Rio Grande do Sul, s/n, Rondon do Pará PA - 68638-00o.
}

Recebido em/Received: 15/08/2020; Aprovado em/Approved: 15/11/2020.

Artigo publicado em acesso aberto sob licença CC BY 4.0 Internacional @)( 
development. Our analysis indicates, among other issues, that in communities with little tradition of local media, dwellers are unable to distinguish journalistic information from other types, bringing down the chances of being well-informed and, ultimately, achieving their status as citizens. Besides to not understand the importance of local information, people are also not available as sources of information, which makes difficult the exercise of journalism in these spaces.

Keywords: News Desert; Journalism; Disinformation; Rondon Notícias; Covid-19.

\section{INTRODUÇÃO}

Enquanto o mundo discutia de forma acirrada e intensa os efeitos da desinformação em contextos de pleitos eleitorais e suas consequências para Estados democráticos, a pandemia da Covid-19, provocada pelo novo coronavírus, trouxe à tona um novo ingrediente ao debate. Viu-se que não apenas eleições ou efeitos nefastos sobre os processos políticos formais poderiam ser profundamente afetados pelo que se convencionou chamar nos estudos contemporâneos de desinformação (Cooke 2018; Cosentino, Gabriele 2020; Delmazzo, Valente 2018; Harsin 2018). No contexto pandêmico, a presença de veículos de imprensa, bem como o papel da comunicação pública, voltaram a ocupar papel de destaque na prestação de informações. Mas, para além da oferta de conteúdo, o provimento de informações qualificadas e fidedignas tornou-se caso de vida ou morte, literalmente.

Diante deste quadro, além de questões sanitárias, como o acesso à água para lavar as mãos, ou econômicas, referentes a condições de compra de álcool em gel ou mesmo a manutenção dos orçamentos familiares e ao desemprego, boas informações tornaram-se prementes no combate à COVID-19. Em outras palavras, o acesso à informação de qualidade tornou-se elemento fundamental na manutenção das condições básicas de saúde pública em muitos países, estados e municípios em todo o mundo.

Neste artigo, discutimos a importância da prestação de informação qualificada, particularmente, aquela promovida pelo jornalismo, em contextos do que alguns estudiosos chamam de deserto de notícias ou desertos de silêncio (Rafsky 2019; Napoli et al 2015). A partir de um contexto bem específico, o da cidade de Rondon do Pará, no Sudeste paraense, buscamos analisar como a escassez de informação jornalística impacta o conhecimento da realidade local, especialmente durante a pandemia. Partindo dos conceitos de jornalismo comunitário e da ideia de desinformação, assumimos a premissa de que a informação jornalística, fundamentada em princípios como os critérios de noticiabilidade, de técnicas de apuração e redação, bem como o objetivo de ir ao encontro do interesse público, tende a ser mais eficaz do que informações difusas ou sem critérios de qualidade que circulam por meio de sites de redes sociais, como o Facebook, e de aplicativos de mensagens instantâneas, como o Whatsapp. Assim, nossa hipótese é a de que, em lugares com meios jornalísticos diversos e que reportam a realidade local, há maior espaço para promoção da cidadania, uma vez que as comunidades podem ter bons subsídios para a tomada de decisões.

Em última instância, visamos contribuir para o debate sobre a relevância do jornalismo em sociedades periféricas, como uma questão de cidadania e de desenvolvimento local. Trata-se de uma discussão que envolve direitos básicos, garantidos em normas nacionais e internacionais, como o direito à saúde e à informação, que impactam sobremaneira nas condições de vida das comunidades locais.

Nossa base empírica parte da experiência de pesquisa de campo realizada em Rondon do Pará. Embora utilizemos dados quantitativos, nossa metodologia é eminentemente 
qualitativa, fundamentada em entrevistas semi-estruturadas com cidadãos rondonenses, e em observação participante, com nossa experiência na rotina de produção do portal Rondon Notícias, projeto de extensão vinculado à Faculdade de Comunicação (Facom) da Universidade Federal do Sul e Sudeste do Pará (Unifesspa).

\section{O CENÁRIO DA PESQUISA}

O fenômeno de escassez de informação jornalística em determinadas regiões, chamado de desertos de notícias, têm se intensificado nas últimas duas décadas. Dados do relatório News Desert and Ghost Newspapers: Will Local News Survive, realizado pela Hussman School of Journalism and Media de la University of North Carolina of Chapel Hil', mostram que, entre 2004 e 2020, foram encerradas as atividades em 2.100 meios de comunicação impressa, o que representa $25 \%$ do total de periódicos diários nos Estados Unidos. Resultado da medida: 200 dos 3.143 municípios norte americanos ficaram sem nenhum jornal em suas realidades mais próximas. A maioria deles, há maior nível de pobreza que a média nacional. Além disso, metade das cidades nos Estados Unidos tem apenas um jornal.

Esse cenário afeta diretamente a diversidade de fontes de informação para as comunidades. O mesmo acontece na América Latina. É o caso da Colômbia onde, segundo a pesquisa Cartografías de la Información ${ }^{2}$, da Fundación Ideas para la Paz, dos 994 municípios mapeados, 578 são zonas de silêncio, ou seja, não possuem meios de informação sobre notícias locais. Essa realidade, que atinge 10 milhões de colombianos, decorre do conflito armado que instala censura em diversas regiões.

No Brasil, desde 2011, 81 veículos foram fechados no Brasil segundo o Atlas da Notícia, iniciativa do Instituto para o Desenvolvimento do Jornalismo (Projor), mantenedor do Observatório da Imprensa, em parceria com Volt Data Lab, inspirado pelo projeto America's Growing News Desert ${ }^{4}$, da revista Columbia Journalism Review.

O relatório, que faz o levantamento dos desertos de notícias no Brasil, divulgado em 2020, mostra que, em pelo menos 3.487 cidades, com média de 7 mil habitantes, não há veículos jornalísticos. Essas localidades, correspondem a $62,6 \%$ dos municípios brasileiros e abrigam 37 milhões de pessoas, ou seja, $18 \%$ da população nacional não podem contar com veículos de informação. Há ainda os quase desertos, que são municípios que possuem apenas um ou dois veículos de comunicação e, em geral, tem população média de 17.800 habitantes. Neste caso, há o problema da pouca concorrência e da vulnerabilidade para interferências políticas ou empresariais.

Estados das regiões Norte e Nordeste são os que possuem uma proporção maior de desertos de notícias. No Pará, segundo a pesquisa, das 144 cidades mapeadas, mais de $60 \%$ são consideradas desertos de notícia, e outros $30 \%$, quase desertos.

Rondon do Pará, cidade com 52.357 habitantes ${ }^{5}$ do Sudeste paraense, tem registrado no Atlas quatro veículos, sendo uma emissora de rádio e três de televisão. Mas, efetivamente, conforme verificamos a partir deste trabalho, o que existe na cidade são

\footnotetext{
${ }^{1}$ Disponível em: https://www.usnewsdeserts.com/

2 Disponível em: https://flip.org.co/cartografias-informacion/

3 Disponível em: https://www.atlas.jor.br/

${ }^{4}$ Disponível em: https://www.cjr.org/local_news/american-news-deserts-donuts-local.php

${ }_{5}^{5}$ Segundo estimativa populacional do Instituto Brasileiro de Geografia e Estatística (IBGE) para 2019.
} 
duas emissoras de rádio, sendo uma comercial e outra comunitária. Não há nenhum veículo impresso jornalístico e nem registro de revista ou jornal impresso nacional ou regional que circule na cidade, nem mesmo da cidade média mais próxima, Marabá, a 155 quilômetros. Também não existe nenhuma agência ou assessoria de imprensa com equipe formada por jornalistas profissionais. Algumas páginas de informações circulam na internet, principalmente em plataformas de mídias digitais, mas o conteúdo não tem caráter jornalístico.

Em 2018, a Universidade Federal do Sul e Sudeste do Pará (Unifesspa) implantou o curso de graduação em Jornalismo na cidade. A ideia era promover a consolidação da instituição por meio da interiorização do Ensino Superior nesta porção da Amazônia. Até aqui, o curso ampliou suas proporções e já possui três turmas regulares, além de promover uma pós-graduação em nível lato sensu em Mídias no Ambiente Escolar.

No âmbito da Faculdade de Comunicação (Facom), são desenvolvidos atualmente nove projetos de pesquisa, três projetos de ensino, e seis ações de extensão, entre programas e projetos. Dentre estes, destaca-se o projeto denominado Portal Rondon Notícias $^{6}(\mathrm{RN})$, o qual detalhamos neste artigo.

O Rondon Notícias nasceu ainda em 2018, como uma das primeiras ações extensionistas do curso de Jornalismo. Vinculado à Paiá - Agência Experimental de Jornalismo, o RN destina-se a promover o jornalismo comunitário, dando ênfase e protagonismo às pautas locais. É o único veículo gerenciado por jornalistas profissionais - que atuam como docentes - da cidade, onde também atuam estudantes de graduação em jornalismo.

Fazem parte da rotina de produção do RN alunos bolsistas e voluntários, docentes da Faculdade, além de colaboradores externos, também voluntários, nas seções de opinião. O único financiamento do portal são as bolsas de extensão, concedidas pela pró-reitoria responsável da Unifesspa.

Conhecido o contexto do qual partimos neste trabalho, buscamos discutir na próxima seção o fenômeno dos desertos de notícia na contemporaneidade.

\section{DESERTO DE NOTÍCIAS NA ERA DA INFORMAÇÃO DIGITAL}

O fechamento de veículos impressos motivou diversas pesquisas sobre os desertos de notícias nos Estados Unidos. Nas últimas décadas, elas tiveram como foco locais onde os principais meios de comunicação, geralmente jornais, fecharam ou nunca chegaram a existir. Estudos como o da Columbia Journalism School e o da Rutger School of Communication and Information observam esses cenários em regiões aparentemente com grande quantidade de meios de comunicação, como Nova lorque e o estado de Nova Jersey, respectivamente.

No caso de Nova Iorque, que concentra $12 \%$ de todos os jornalistas nos EUA, segundo Pew Research Center de $2019^{7}$, apesar da alta concentração de empresas de mídia, a cobertura local da cidade vive uma crise semelhante à que assola a indústria de notícias em áreas menos prósperas. Rafsky (2019), no estudo da Columbia Journalism School, mostra, dentre outros fatores, que determinados assuntos são subnotificados e outros são tratados de forma generalista e não mais com foco em problemas específicos de

\footnotetext{
${ }^{6}$ Disponível em: https://rondonnoticias.com/

7 Disponível em: https://www.pewresearch.org/fact-tank/2019/10/24/one-in-five-u-s-newsroom-employees-live-in-newyork-los-angeles-or-d-cl
} 
bairros ou regiões, além de uma clara tensão causada pela necessidade de ampliar a audiência para obter mais investimento em publicidade ao mesmo tempo que se limita a um público menor.

O estudo realizado em três cidade de Nova Jersey pela Rutgers (Napoli et al. 2015), que compara três cidades de porte diferentes, observou que havia menos serviço jornalístico nas comunidades de baixa renda, e uma proporção menor dessa produção jornalística atendia a critérios básicos de qualidade quando comparada a uma comunidade maior. "Essa falta de acesso a notícias representa um perigo de longo alcance para o envolvimento cívico, a responsabilidade do governo e, segundo muitos analistas, a própria democracia" (Miller 2018, p. 59).

Embora estejamos em um contexto de hiperconexão global, em que as nossas formas de socialização ocorrem, simultaneamente em espaços digitais e não digitais (Ellison, Boyd 2013), o nível de acesso a informações qualificadas é heterogêneo. Esta realidade denota, portanto, que a quantidade de informações atualmente disponíveis não é exatamente compatível ou não dialoga diretamente com o direito e o acesso à informação de qualidade. Há, em um sem-número de pesquisas atuais, uma divisão quanto à positividade ou não dos recursos disponíveis para a participação política, para o exercício da cidadania e de experiências mais democráticas relacionadas, por exemplo, à internet e ao jornalismo (Maia, Prudêncio, Vimieiro 2018; Mato, Alonso, 2005; Vicente, Soares, 2017).

Os desertos de notícias, mesmo diante da profunda incorporação de dispositivos de mídias digitais, provocada principalmente pela popularização dos smartphones e da internet móvel, persistem. Esse fenômeno é, em larga medida, uma das causas da chamada desinformação, analisada por diferentes prismas de teóricos sociais da comunicação, mas não a única. Mesmo em locais com grande volume de informações, a desinformação está presente devido à concentração da propriedade dos meios de comunicação e, consequente, da cobertura homogeneizada dos fatos. A carga informacional disponibilizada diariamente gera uma sensação de caos que dificulta a percepção entre as notícias verdadeiras e falsas. Nos desertos de notícias, esse problema incide principalmente sobre as informações locais.

Na próxima seção, discutiremos o conceito de desinformação, como parte do processo mais amplo que relaciona acesso à informação e democracia, no contexto da crise de saúde global, provocada pela proliferação do novo coronavírus.

\section{A DESINFORMAÇÃO E A PANDEMIA DA COVID-19}

A precarização do acesso à informação, seja por meio da ausência de qualidade do material noticioso ou simplesmente pela falta de oferta de notícias e outras consequências, como a produção de fake news, entendidas aqui como "artigos noticiosos intencionalmente falsos e capazes de serem verificados como tal, e que podem enganar os leitores" (Allcott e Gentzkow 2017, p. 4, tradução nossa) vai ao encontro do que muitos autores têm chamado de desinformação (Bennett; Livingston, 2018; Correia, 2019; Cosentino, 2020; Delmazo; Valente, 2018). Essa conceituação busca ampliar o olhar sobre o fenômeno das crises das democracias contemporâneas lançando um olhar particular sobre o papel da imprensa e das empresas proprietárias de plataformas de mídias digitais e a importância do direito à informação.

Tal discussão nos leva a uma outra dimensão do problema: nesta era, em que informações difusas e informais ganharam aparência e status de notícia, muitas vezes sendo as únicas fontes de informação de grandes públicos, as sociedades precisam ser 
cada vez mais capazes de identificar a veracidade das informações e a qualidade desses conteúdos.

Embora haja uma sensação de excesso de informação sobre a pandemia, é preciso pontuar o crescimento das informações desqualificadas e falsas, o que Posetii e Bontcheva (2020) chamam de desinfodemia, "o que é falso tem um impacto potencialmente negativo. Estes impactos podem ter consequências fatais durante a pandemia" (Posetii, Bontcheva 2020, p. 2, tradução nossa). Acrescenta-se a isso o fato de que as chamadas fake news (Allcott, Gentzkow 2017) aparecem em meio a "notícias verdadeiras" e com formatos familiares à audiência, fortemente verossímil.

O acesso à internet é, portanto, ao mesmo, uma forma de enfrentar a COVID-19 e um meio eficiente de divulgação de informações falsas. A conexão permite que as pessoas se mantenham ativas em atividades como trabalho, estudos e relações sociais, à distância; possibilita o acesso à informação direta do governo e organismos de saúde; e permite que o jornalismo de referência chegue a públicos maiores.

Por outro lado, a "desinfodemia" faz com que muitas pessoas sejam enganadas e percam a possibilidade de compreender e aplicar as medidas preventivas baseadas na ciência. Alguns recorrem a remédios sem comprovação científica ou negam a existência da doença. Além disso, a informação online pode ser instrumentalizada para fins políticos, para polarizar a discussão e danificar a credibilidade dos veículos de comunicação qualificados (Posetii, Bontcheva 2020). Mas, são justamente os meios digitais os que mais tomaram importância durante a pandemia. Neste período o tempo de conexão à internet cresceu em todo o mundo. De acordo com a pesquisa Digital $2020^{8}, 70 \%$ dos entrevistados passaram a usar mais o smartphone e $47 \%$ aumentaram o tempo à frente do computador.

A internet também tem auxiliado na busca de informações sobre a COVID-19. Cerca de $83 \%$ dos pesquisados dizem se manter informados sobre medidas de isolamento social por esse meio. No Brasil, a pesquisa mostra que $80 \%$ das pessoas com mais de 13 anos usam as mídias digitais, e que cada pessoa tem cerca de 8 contas em diferentes plataformas.

No entanto, em paralelo a esse fenômeno, constata-se o fechamento de veículos de imprensa durante a pandemia, como detalhado anteriormente. Redução ou suspensão de edições impressas, programas televisivos e radiofônicos e portais de notícias, cortes salariais e demissões em massa têm sido a "solução" para empresas de informação, justamente durante o momento em que o trabalho jornalístico se mostra essencial para a sociedade.

A Associação Nacional de Jornais (ANJ) estima que 30 veículos foram fechados devido à crise econômica decorrente da pandemia. "Nós estamos correndo risco muito sério de vastas regiões do Brasil ficarem sem nenhum veículo de jornalismo profissional. E onde não há jornalismo profissional, a tendência é que esse lugar seja ocupado por uma onda de desinformação", disse o presidente da ANJ, Marcelo Antônio Rech, em entrevista9.

\footnotetext{
${ }^{8}$ Disponível em: https://wearesocial.com/digital-2020

9 Disponível em: https://espacopb.com.br/v/mais-de-3o-veiculos-de-comunicacao-ja-fecharam-as-portas-durante-acrise-sanitaria?fbclid=IwARolIA_yH56wNW1xum6XmYTddkh-gvzfMLTygAzhiY3LMt3Z2nIYxIQcsLM
} 
Esse cenário tende a abrir lacunas enormes no fluxo informativo, principalmente em cidades pequenas e do interior do Brasil. São esses problemas do acesso à informação e o papel do jornalismo no interior do país que discutiremos a seguir.

\section{ACESSO À INFORMAÇÃO E O JORNALISMO NO INTERIOR}

O acesso à informação é um elemento fundamental para o processo de desenvolvimento de sociedades democráticas (Gomes, Maia 2008). Com a reconfiguração dos meios de comunicação a partir das tecnologias e dos sistemas de comunicação em rede, alguns elementos são acrescidos a esse processo. Um deles é a acessibilidade à informação. A sociedade em rede (Castells 1999) propiciou, entre outras coisas, a possibilidade de divulgar e acessar informações por meio de grupos formais e informais disponíveis na internet; a formação de locais de diálogos públicos sobre problemáticas comuns; a aproximação da sociedade com os órgãos governamentais; a disponibilidade de dados necessários para discussões públicas e tomadas de decisão; a reunião de grupos identitários e também a exposição de realidade regionais. Especialmente, sobre este último ponto, nota-se a dificuldade de articulação de canais informativos locais.

Para Ferrucci e Alaimo (2019), a lógica empresarial contribuiu ao longo dos anos para o fim do jornalismo local em alguns lugares do Estados Unidos. Os veículos locais, pertencentes a famílias da comunidade, aos poucos foram comprados por grandes conglomerados. Quando as margens de lucro das organizações de notícias começaram a diminuir, esses conglomerados reagiram reduzindo significativamente 0 investimento econômico em suas redações e fechando algumas. Quando existe a possibilidade de fazer jornalismo local, alguns meios enfrentam problemas como o atraso na informação, a falta de profundidade, a escassez de profissionais, os constrangimentos sociais e as dificuldades financeiras, observadas no estudo de Cardoso (2020) sobre a cidade de Arouca, em Portugal.

A interiorização dos cursos de Jornalismo tem contribuído para um cenário de profissionalização em locais distantes dos centros onde já existem diversas empresas de comunicação. Nas regiões periféricas onde prevalecem a precarização técnica e ética, além dos desafios ligados a questões culturais e educacionais, as barreiras geográficas e logísticas levam a uma maior sensação de isolamento (Serpa, Colferai 2015).

Na região Norte, alguns exemplos de interiorização das universidades têm levado a possibilidade da imbricação entre o conhecimento advindo da academia e a prática cotidiana da mídia do interior para produção de um jornalismo experimental. Mas essa realidade é privilégio de poucos locais, tendo a maioria das localidades um déficit de material informativo comunitário que atenda às principais demandas das regiões interioranas.

\section{INFORMAÇÃO QUALIFICADA, JORNALISMO COMUNITÁRIO E DESENVOLVIMENTO LOCAL}

Embora se constate a facilidade da distribuição e acesso à informação nos meios digitais, elementos importantes para o desenvolvimento, é necessário analisar esse fenômeno desde o ponto de vista do que chamaremos de "informação qualificada", ou seja, produções jornalísticas produzidas de forma profissional que levam em consideração alguns atributos indispensáveis. 
Para diferenciar informação de informação jornalística, Reginato (2020) defende que se aponte como finalidade do jornalismo "informar de modo qualificado". Para isso, é necessário que esse jornalismo cumpra algumas exigências como: 1) informação verificada: necessidade de fontes identificáveis dedicadas à verificação das informações; 2) informação relevante: "a partir do que é relevante, enquadrar a matéria pela relevância do assunto em si, ampliando o conhecimento do leitor sobre algum tema específico e sobre o mundo para que ele possa atribuir sentido aos acontecimentos"; 3) informação contextualizada: colocá-la em um quadro de significados que sejam familiares ao público; 4) informação plural: revelar pontos de vista diferentes e oferecer espaço para multiplicidade de opiniões; 5) informação envolvente: técnicas narrativas e elementos visuais que sejam atrativos e facilitem a leitura de temas complexos.

Christofoletti (2010), na busca por indicadores da qualidade no jornalismo, compartilha de algumas premissas listadas e acrescenta: a independência editorial, a transparência na gestão e a preocupação com o impacto dos conteúdos na sociedade. Guerra (2010) distingue a questão da qualidade em: interna, se atender às especificações da organização; e externa, se produzida de acordo com especificações da organização e se estas também coincidirem com as expectativas de qualidade da audiência (verdade, relevância e pluralidade).

Além desses indicadores, no contexto das informações locais, é de fundamental importância abordar como premissa o jornalismo comunitário, que objetiva atender aos interesses da comunidade por meio das pautas e das fontes utilizadas, principalmente aquelas que representam a problemática local. Para Peruzzo (2003), uma das características mais importantes é que o veículo tenha o objetivo de divulgar acontecimentos das comunidades/movimentos coletivos que ele atende, que sejam de interesse público, e que raramente será pautado pela mídia convencional. Outra característica é o uso de pessoas da comunidade na participação da elaboração do conteúdo que está sendo produzido para ser veiculado - aqui entra a participação do receptor, que pode ser produtor de conteúdo, entrevistado, editor etc. - e quem vai produzir ou pautar a mídia comunitária não é obrigatoriamente um jornalista ou especialista na área, mas pode ser o cidadão comum. Além das características já mencionadas, a autora destaca que fazer comunicação comunitária é ter como objetivo contribuir com a garantia dos direitos da comunidade, sobretudo, do direito à informação.

Esse movimento busca romper com práticas de comunicação vinculadas a modelos desenvolvimentistas exógenos, isto é, aqueles projetados e implementados de fora para dentro das comunidades, com caráter hierárquico, em que o que é externo exerce poder sobre o local. Disso decorre o rompimento de uma subalternização da comunidade local, que, em processos ordinários da indústria da mídia, é alijada de práticas comunicativas em que possa se ver, se construir, se reproduzir socialmente e acionar suas condições sociais de cidadania.

Práticas comunicativas participativas possibilitam o reconhecimento do poder de ação dos atores dentro de um coletivo. A comunicação ajuda na conformação desse coletivo, fortalecendo, portanto, práticas cívicas. Nesse sentido, estamos nos referindo à comunicação para o desenvolvimento e mudança social (Cimadevilla 2012, Cosude 2014). Trata-se de uma "perspectiva cidadã" na comunicação voltada à transformação (Tufte 2017).

A comunicação para o desenvolvimento, prevê, assim, possibilidades de expressão dos atores locais e também formas participativas de engajamento desses atores. Isso visa à construção de espaços democráticos de construção e fortalecimento de laços locais, 
bem como a consecução de direitos a partir de concepções elaboradas no interior das comunidades.

A relação de engajamento com cidadãos locais é possível de diversas maneiras, incluindo a participação de organizações governamentais e não-governamentais. Aqui, destacamos o papel das instituições federais de ensino (IFEs), particularmente, o da Unifesspa, no contexto de Rondon do Pará, com seu curso de Jornalismo. A formação de futuros jornalistas locais, bem como a priorização de projetos de natureza comunitária e participativa vão ao encontro da perspectiva apontada por Tufte (2017), em que a participação e o protagonismo dos atores locais ganha papel central.

\section{PROCEDIMENTOS METODOLÓGICOS}

Esta pesquisa configura como um esforço inicial, de caráter experimental, em que buscamos apreender de maneira panorâmica a maneira pela qual os cidadãos de Rondon do Pará se informam, especialmente, sobre a pandemia da Covid-19.

Para isso, elaboramos um formulário online em que os respondentes foram questionados em três principais eixos: a) sobre suas identificações básicas, como gênero, idade, escolaridade e renda; b) sobre as fontes de informações a que recorrem, uso específico do whatsapp e de informações jornalísticas; c) sobre a credibilidade dos meios.

Para este trabalho, nos concentramos nas seguintes questões: como a escassez de informação jornalística impacta o conhecimento da realidade local, especialmente durante a pandemia? Tal questão, pode ainda ser compreendida por duas subquestões: Como os cidadãos que vivem em desertos de notícias, como Rondon do Pará, suprem suas necessidades informativas locais sobre a Covid-19? De que forma compreendem o papel do jornalismo na produção de notícias qualificadas?

O formulário de questões estruturadas e semi-estruturadas (Flick 2014), foi elaborado com o uso do Google Forms e as perguntas foram feitas por telefone devido à própria pandemia - que nos condicionou ao isolamento social. Os dados foram coletados entre os meses de junho e julho de 2020. Nossa amostra, configurada por conveniência (Carvalho 2008), consistiu em 19 participantes. Embora pequeno, nosso " $n$ " não se propõe a validações estatísticas, mas muito mais em uma amostra qualitativamente representativa, buscando abranger perfis razoavelmente diferentes.

Nesse sentido, mesmo considerando os dados numéricos relevantes para fins de generalizações mínimas, nossa análise é prioritariamente qualitativa. O presente trabalho, então, configura-se como um esforço inicial de compreensão da realidade de Rondon do Pará no que diz respeito à importância da informação jornalística neste contexto adverso de insipiência de jornalismo e de forte impacto na saúde coletiva.

Recorremos também a uma observação participante (Angrosino 2009) para análise das rotinas produtivas do portal Rondon Notícias. Foram observados dois fatores específicos para esta análise: a relação com as fontes e a relação com a audiência. Como integrantes do projeto desde a sua concepção, em agosto de 2018, realizamos, em conjunto com os discentes, toda concepção e acompanhamento do processo de implantação do site e perfis e páginas nas plataformas de mídias digitais e participamos ativamente na elaboração e execução das pautas, bem como na supervisão e contato direto com fontes e audiência. A observação participante, considera, portanto, cerca de 24 meses de trabalhos ininterruptos em que estivemos na rotina produtiva do RN. 


\section{RESULTADOS E DISCUSSÃO}

\section{Resultados}

A partir das questões elaboradas, temos um perfil básico de nossos respondentes com os seguintes atributos: a maioria é do gênero feminino (57,9\%). Parcela significativa dos resultados aponta exercício de trabalho de nível superior (42,1\%), e uma segunda parcela significativa demonstra atividades de trabalho relacionadas à vida doméstica ou ao desemprego (26,31\%). $63,3 \%$ dos participantes têm ou já tiveram acesso à formação de nível superior (superior completo, incompleto e pós-graduação). Todos têm mais de 18 anos e a maioria (89,6\%) ocupa a faixa etária de 24 a 55 anos. A maior parte $(63,1 \%)$ possui renda de até um salário mínimo.

Em relação às questões sobre a circulação de informações, preferências temáticas e os meios pelos quais as pessoas de Rondon do Pará se informam temos o seguinte panorama: a maioria (39\%) dos nossos entrevistados têm interesses por temas relacionados à saúde, o que reforça a importância do engajamento em informações qualificadas, já que a natureza das questões podem incidir diretamente na vida das pessoas.

Em relação aos tipos de informação que os nossos interlocutores recebem, têm destaque aqueles relacionados a pessoas comuns, em que elas mesmas são autoras dos conteúdos ( $58 \%$ do conteúdo). Informações oriundas de meios de comunicação estão em segundo lugar, com 35\%; informações de jornalistas (pessoas individuais, figuras públicas da comunicação), correspondem a $6 \% ; 1 \%$ se refere a todas as opções.

Mais da metade dos entrevistados, $53 \%$, afirma que as "redes sociais" (sites de redes sociais) são os principais meios de recebimento de informações sobre o coronavírus em Rondon do Pará; 32\% têm o Whatsapp como principal meio de se informar; $10 \%$ recorrem a sites variados e $5 \%$ a rádios.

Dos respondentes, 72,2\% afirmam receber informações advindas, principalmente, de grupos. A natureza dessas unidades sociais online (Bargas 2018) está destacadamente relacionada à família, a organizações religiosas, educacionais e profissionais.

Outro dado relevante da pesquisa: $72 \%$ dos entrevistados afirmam que apenas às vezes, abrem links que recebem. Esse dado aponta que elas tendem a se informar por tipos de conteúdos gráficos ou audiovisuais, que não necessitam de muitos cliques ou mudança de ambiente para serem consumidos, tais como memes, cards, áudios, figurinhas ou vídeos.

Em relação à identificação do tipo de informações que recebem, a maioria (50\%) dos respondentes considera que tais informações não são jornalísticas. Entre todos, 33\% consideram que são informações jornalísticas. Os demais (17\%) consideram que as informações são parcialmente jornalísticas.

Quando perguntados sobre como identificam se as informações são jornalísticas, boa parte dos participantes afirmam que elementos como o tipo de texto, as fontes consultadas e os detalhes das informações são os principais quesitos observados. Além desses dados, o que ainda que chama atenção é que pouco mais de $15 \%$ dos respondentes não soube responder à questão. Também destaca-se o fato de que todos afirmaram não confiar nas mensagens que recebem pelos grupos. 
Particularmente sobre a primeira morte por Covid-19 em Rondon do Pará, 33,3\% dos entrevistados afirmaram ter tido dúvida sobre tal notícia. As principais categorias utilizadas por eles para desacreditarem na informação são: as fontes ou remetentes desconhecidos e o quadro atual de intensa difusão de notícias falsas.

Metade dos entrevistados afirma não considerar que os conteúdos consumidos por eles sejam de natureza jornalística. No entanto, ao aplicarmos a pergunta, em alguns casos tivemos que explicar os quesitos básicos sobre o que seria jornalístico. O mesmo não aconteceu para a parte dos entrevistados com maior nível de escolaridade. Isso pode significar que, de forma geral, a linguagem jornalística se difundiu e se tornou comum para conteúdos informativos gerais que circulam na web a ponto de não poder ser distinguida. Ou, por outro lado, pode significar um tipo de formato "elitizado" que apenas cidadãos com formação em níveis superiores conseguem verificar. De fato, nossa pesquisa não permite fazer nenhuma dessas afirmações. No entanto, nos parece útil pensar sobre o papel cada vez mais importante de quesitos relacionados mais à produção da notícia do que o formato, já que buscamos analisar a forma pelas quais as pessoas buscam informações qualificadas do ponto de vista de sua veracidade e utilidade.

Outro ponto importante observado a partir das entrevistas é que quase todos os entrevistados recebem informações via Whatsapp, mas não confiam plenamente nessas informações. A mensagem original se perde, e com ela a fonte/remetente, e a maioria (52,9\%) dos participantes diz que não saber a proveniência. Nesse caso, vale a questão: se não confiam, como se informam? Qual o nível de segurança desses cidadãos em relação à maneira pela qual se informam? Uma resposta parcial a estas questões está no fato de que os respondentes afirmam buscar sites institucionais. No caso de informações sobre o novo coronavírus, os entrevistados afirmaram buscar informações nos canais oficiais da Prefeitura Municipal de Rondon do Pará nas redes sociais, uma vez que a fonte é um órgão público. Ou seja, a prefeitura é a principal fonte de informação sobre as questões que envolvem a pandemia, o que denota, no contexto de produção de informações a importância da adoção de políticas de comunicação institucional pública por parte da gestão municipal e de outros órgãos públicos.

Em outras palavras, além do esforço de interiorização de cursos de jornalismo e de ações experimentais em contextos de desertos de notícias, a pandemia da COVID-19 conduz os poderes executivo e legislativo municipais a dever serem capazes de incorporar princípios e profissionais do jornalismo em seus quadros com vista ao exercício de uma boa comunicação pública (Weber 2017).

A partir de nossa observação participante, é possível afirmar que, em relação ao Rondon Notícias, assim como diversos veículos de mídia locais, a internet foi o meio facilitador para o suporte. No caso do site, hospedado na plataforma Wordpress, alguns picos de visualização são um termômetro dos assuntos que mais interessam ao público.

Na cobertura especial sobre a Covid-19 há uma audiência expressiva, com mais de mil visualizações em uma reportagem sobre a morte de profissionais de saúde em decorrência da Covid-19. Entretanto, algumas matérias de interesse público e sem nenhuma cobertura de outros veículos, como o caso do acompanhamento das sessões da Câmara de Vereadores, costumam ter poucas visualizações ou nenhuma.

Nas plataformas de mídias digitais, tanto o Facebook como o Instagram, o RN tem um envolvimento ainda modesto com a audiência, com cerca de 1.500 seguidores em cada 
uma. O alcance, no entanto, que chega a mais de 500 pessoas no pico, é totalmente orgânico, sem nenhum investimento.

Um caso específico, também abstraído da observação participante, vale ser considerado: na produção de reportagens sobre a Covid-19 em Rondon do Pará, a equipe do RN optou por realizar coberturas mais aprofundadas, em contraposição ao factual. Buscamos fontes de diversos pontos de vista sobre o caso da primeira morte pela doença no município. A reportagem, que percorreu mais de um mês em desenvolvimento desde a concepção da pauta, passando pelos processos de apuração, até a publicação, passou por dificuldades nos relacionamentos com as fontes oficiais, especialmente da prefeitura. Houve discordância sobre as informações contidas na matéria, além de dificuldades em contatos futuros. Tal situação demonstra a necessidade de ampliação do entendimento sobre o papel do jornalismo tanto entre fontes oficiais quanto não oficiais. Ao fim, o exercício do jornalismo é prejudicado devido à morosidade e burocratização no acesso aos dados. Esse é um exemplo concreto do quanto as barreiras ao jornalismo podem ofuscar as possibilidades do acesso à informação de qualidade.

\section{Discussão}

De fato, o caso de Rondon do Pará configura-se como um deserto de notícias (Napoli et al. 2015). Os três níveis de análise para esta constatação, segundo Napoli et al (2015) são aqui observados. Não há disponibilidade de meios de comunicação de caráter jornalístico (infraestrutura), não há produção de conteúdo jornalístico nem profissionais da área atuando no município (produção) e o conteúdo que circula como elemento de informação pelos cidadãos rondonenses não traz originalidade e tampouco oferece uma abordagem centrada na população local, atendendo às suas necessidades (desempenho).

As fontes de informação são basicamente plataformas de mídias digitais, em que se destacam sites de redes sociais, como o Facebook e Instagram, e aplicativos de trocas de mensagens instantâneas, como o Whatsapp. Isso denota a forte incorporação (Hine 2015; Ellison, Boyd 2013) das mídias digitais entre os rondonenses, e segue a tendência global de domínio dessas plataformas dos circuitos culturais e de informação. Segue também a tendência da desinformação, em que conteúdos de qualidade questionável acabam cumprindo o papel do jornalismo, mediando a relação dos cidadãos com os sistemas cultural, social e político do local (Cooke 2018).

A forte desconfiança de nossos entrevistados em relação à qualidade ou mesmo a veracidade das informações recebidas reforça as análises de que as fake news fazem parte desse processos (Delmazzo, Valente 2018) e que, especificamente durante a pandemia da Covid-19, isso se tornou um fenômeno patológico, na medida em que leva pessoas a riscos de vida. Duas epidemias ao mesmo tempo, ou a infodemia, para usar os termos de Posetii e Bontcheva (2020).

O fato de que as pessoas não abrem links que recebem também se destaca nesse contexto em que elas tendem a se informar apenas em um nível superficial sem a leitura de um conteúdo com várias fontes e pontos de vista sobre o assunto em tela. Esse acaba se configurando como um terreno extremamente fértil e para o sistema lucrativo por trás das fake news (Delmazzo, Valente 2018).

A informação digital circula seguindo a mesma lógica das relações sociais primárias, isto é, aquelas relacionadas ao contato imediato das pessoas. Seguindo a tendência da onda de desinformação que, segundo alguns teóricos, são típicos do da era da "pós- 
verdade" (Cooke 2018; Harsin 2018; Cosentino, Gabriele 2020), há aqui ao apelo emocional e até religioso. Grupos que haviam perdido espaço no debate público, como as igrejas, voltaram a ser centrais para a compreensão de mundo dos cidadãos ao se colocarem como emissores de informações e produtores de conteúdos particulares e estrategicamente dirigidos.

Se há dúvidas sobre as maneiras pelas quais se informar e sobre a qualidade das informações obtidas, como os cidadãos rondoneses podem ter informações úteis para exercerem sua cidadania? Tal questão incide justamente no nosso argumento de que a presença de ações, profissionais e conteúdo jornalístico de caráter comunitário tende a reverter esta questão. Faz-se necessário acionar estratégias de comunicação para o desenvolvimento local, ampliando práticas participativas e engajando a comunidade nesses processos (Tufte 2017).

Aqui, o papel do Rondon Notícias ganha destaque. No que diz respeito ao RN, o curso de Jornalismo, inserido neste contexto, principalmente nas atividades de ensino e extensão, atua diretamente nesta realidade ao aproximar-se da comunidade para a produção de conteúdo prático. O projeto de extensão Rondon Notícias propicia o engajamento de alunos e professores com a população local, tanto urbana como rural, interiorizando, portanto, conteúdos acurados (Serpa, Colferai 2015).

$\mathrm{Na}$ observação participante nos deparamos com alguns aspectos relevantes que nos auxiliam na reflexão sobre a inserção de produtos jornalísticos em um deserto de notícias, onde a comunidade está pouco habituada com conteúdos informativos locais qualificados. O portal, embora seja uma experiência laboratorial, consegue abranger uma gama importante de assuntos sobre a cidade, além de buscar qualidade de produção a partir de indicadores listados por Christofoletti (2010), Reginato (2020) e Guerra (2010), como a independência editorial, verificação da informação, relevância, pluralidade de vozes e pontos de vistas, estética envolvente, transparência na gestão e preocupação com o impacto dos conteúdos na sociedade.

Além disso, a partir da premissa de jornalismo comunitário (Peruzzo 2003), o portal objetiva, dentre outras coisas, debater propostas coletivas, ter autonomia em relação ao governo e outros grupos de interesse, produzir conteúdo que aborde as necessidades locais e dar espaço para movimentos coletivos e grupos que normalmente não encontram espaço na mídia convencional.

Ainda que o jornalismo feito seja balizado por esses preceitos, é importante observar a difícil penetração na comunidade para consolidar-se como um veículo de referência. O portal, bem como as redes sociais, está em constante atividade de forma a atrair audiência, mas com uma aderência ainda limitada na comunidade. Também a dificuldade de aproximação com as fontes, principalmente as oficiais e especialistas, evidencia a pouca consciência sobre a importância de um veículo jornalístico. Além dos membros dos poderes executivo, legislativo e judiciário do município, é constante a tentativa de criar laços com a sociedade civil organizada tanto para divulgar fatos de interesse público quanto para esclarecer assuntos que surjam na comunidade.

\section{CONCLUSÃO}

Já existe certo consenso na literatura acadêmica de várias disciplinas particulares sobre o papel do jornalismo como pilar da democracia. No entanto, o acesso a informação de qualidade, em particular do conteúdo jornalístico, não se concretiza igualmente para todos no Brasil. 
Nos desertos de notícia, a exemplo de Rondon do Pará, cidadãos são enredados pela atratividade das plataformas de mídias digitais, hoje amplamente cobradas a se responsabilizar pelas informações que nelas circulam a fim de prevenirem o fenômeno da desinformação e das fake news.

Exatamente durante a pandemia da Covid-19, esses fenômenos passaram a preocupar justamente pelo caráter perverso de sua natureza econômica que pode colocar em xeque a vida de milhões de pessoas mal informadas ou desinformadas. Assim, o jornalismo pode atuar como um remédio a partir de seus princípios imanentes voltados ao interesse público. Apuração responsável, pluralidade de fontes e versões de um fato e compromisso ético, aparecem hoje como fundamentais ao combate ao coronavírus.

Interiorizado e praticado de forma participativa de modo a produzir uma comunicação endógena, vinculada aos interesses locais, o conteúdo jornalístico tem o potencial, então, de promover a cidadania e o desenvolvimento local. O caso do Rondon Notícias nos parece representativo de uma iniciativa que, embora ainda embrionária, tende a transformar a realidade comunicativa de Rondon do Pará.

\section{REFERÊNCIAS}

ALLCOTT, Hunt; GENTZKOW, Matthew. Social media and fake news in the 2016 election. Journal of Economic Perspectives, v. 31, n. 2, p. 211-236, maio 2017. Disponível em: https://www.aeaweb.org/articles?id=10.1257/jep.31.2.211. Acesso em: 13 ago. 2020.

ANGROSINO, Michael V. Etnografia e observação participante. São Paulo: Artmed Editora, 2009.

BARGAS, Janine de Kássia Rocha. Quilombolas do Pará e mídias digitais: sociabilidade, conflito e mobilização online nas lutas por reconhecimento. 2018. Disponível em: http://www.bibliotecadigital.ufmg.br/dspace/handle/1843/BUOS-BgDHN6. Acesso em: 4 set. 2019.

BENNETT, Lance; LIVINGSTON, Steven. The disinformation order: disruptive communication and the decline of democratic institutions. European Journal of Communication, v. 33, n. 2, p. 122-139, 2018. Disponível em: https://doi.org/10.1177/0267323118760317. Acesso em: 10 ago. 2020.

CARDOSO, Cátia, Jornalismo local, cultura e património: o caso de Arouca. In: JERÓNIMO, P.; CORREIA, J. C. O pulsar da proximidade nos media e no jornalismo. Covilhã: LabCom - Comunicação e Artes, 2018.

CASTELLS, Manuel. A sociedade em rede. São Paulo: Paz e Terra, 1999.

CARVALHO, Maria Cecília Maringoni de. Construindo o saber metodologia científica: fundamentos e técnicas. Campinas: Papirus, 2008.

CHRISTOFOLETTI, Rogério (coord.). Vitrine e vidraça: crítica de mídia e qualidade no Jornalismo. Portugal: Labcom Books, 2010.

COOKE, Nicole A. Fake news and alternative facts: information literacy in a post-truth era. Chicago: ALA Editions, 2018. 
CORREIA, João Carlos. O novo ecossistema mediático e a desinformação como estratégia política dos populismos. Estudos em Jornalismo e Mídia, v. 16, n. 2, p. 23-32, 2019. Disponível em:

https://periodicos.ufsc.br/index.php/jornalismo/article/view/1984-6924.2019v16n2p23. Acesso em: 10 ago. 2020.

COSENTINO, Gabriele. Social media and the post-truth world order: the global dynamics of disinformation. [S.I.]: Springer Nature, 2020.

DELMAZO, Caroline; VALENTE, Jonas C. L. Fake news nas redes sociais online: propagação e reações à desinformação em busca de cliques. Media \&amp Jornalismo, v. 18, n. 32, p. 155-169, 2018. Disponível em: http://www.scielo.mec.pt/scielo.php?script=sci_abstract\&pid=S218354622018000100012\&lng=pt\&nrm=iso\&tlng=pt. Acesso em 10 agosto 2020.

ELLISON, Nicole; BOYD, Danah. Sociality through social network sites. In: THE OXFORD handbook of internet studies. Oxford: Oxford University Press, 2013.

FERRUCI, Patrick; ALAIMO, Kathleen I. Escaping the news desert: nonprofit news and open-system journalism organizations. Journalism, v. 21, n. 4, p. 489-506, 2019. Disponível em: https://doi.org/10.1177/1464884919886437. Acesso em: 10 jul. 2020.

FLICK, Uwe (org.). The SAGE handbook of qualitative data analysis. Los Angeles: SAGE, 2014.

GUERRA, Josenildo Luiz. Avaliação de qualidade jornalística: desenvolvendo uma metodologia a partir da análise da cobertura sobre segurança pública. In: VITRINE e vidraça: crítica de mídia e qualidade no jornalismo. Portugal: Labcom Books, 2010.

HARSIN, Jayson. Post-truth and critical communication studies. In: HARSIN, Jayson. Oxford Research Encyclopedia of Communication. Oxford University Press, 2018. Disponível em:

https://oxfordre.com/communication/view/10.1093/acrefore/9780190228613.001.0001/ acrefore-9780190228613-e-757. Acesso em: 10 ago. 2020.

HINE, Christine. Ethnography for the internet: embedded, embodied and everyday. London; New York: Bloomsbury Academic, 2015.

MAIA, Rousiley; PRUDENCIO, Kelly; VIMIEIRO, Ana Carolina (orgs.). Democracia em ambientes digitais: eleições, esfera pública e ativismo. Salvador: EDUFBA, 2018.

MATO, Daniel; ALONSO, Guiomar (orgs.). Cultura, política y sociedad: perspectivas latinoamericanas (antología). 1. ed. Buenos Aires: CLACSO, 2005.

MILLER, J. News deserts: no news is bad news. In: HENDRIX, M. (ed.). Urban policy. New York: Manhattan Institute, 2018. P. 59-76.

PERUZZO, Cicilia M. Krohling. Mídia local e sua interface com a mídia comunitária. In: CONGRESSO BRASILEIRO DE CIÊNCIAS DA COMUNICAÇÃO, 25., 2003, Belo Horizonte. Anais eletrônicos... 2013. Disponível em:

http://www.portcom.intercom.org.br/pdfs/990610995418133244990372819948585011 01.pdf. Acesso em: ago. 2020. 
POSETTI, Julie; BONTCHEVA, Kalina. Disinfodemic: deciphering COVID-19

disinformation. Unesco, 2020. Disponível em:

https://en.unesco.org/sites/default/files/disinfodemic_deciphering_covid19_disinform ation.pdf. Acesso em: 30 maio 2020.

RAFSKY, Sara G. Media mecca or news desert?: covering local news in New York city: Town Center for Digital Journalism. Columbia: Columbia University, 2020. Disponível em: https://academiccommons.columbia.edu/doi/10.7916/d8-69sr-1m91. Acesso em: ago. 2020.

REGINATO, Gisele Dotto. Informar de modo qualificado: a finalidade central do jornalismo nas sociedades democráticas. Estudos em Jornalismo e Mídia, v. 17, n. 1, p. 43-53, 2020. Disponível em:

https://periodicos.ufsc.br/index.php/jornalismo/article/view/1984-6924.2020v17 n1p43/ 4359. Acesso em: ago. 2020.

SERPA, Leoní; COLFERAI, Sandro. Desafios e perspectivas no ensino de jornalismo no interior da Amazônia: o caso de Vilhena-RO. Manaus, AM: UFAM, 2015. Disponível em: https://www.portalintercom.org.br/anais/norte2015/resumos/R44-0547-1.pdf. Acesso em: 12 jul. 2020.

VICENTE, Maximiliano Martín; SOARES, Murilo César (orgs.). Comunicação e cidadania política. São Paulo: Cultura Acadêmica, 2017. Disponível em:

http://www.faac.unesp.br/Home/Utilidades/ebook_comunicacao-e-cidadaniapolitica.pdf. Acesso em: 2020. 